\title{
PARAMETRIC MODELLING OF TEMPORAL VARIATIONS IN RADON CONCENTRATIONS IN HOMES
}

\author{
K.L. Revzan, B.H. Turk, J. Harrison, A.V. Nero, R.G. Sextro \\ Indoor Environment Program \\ Lawrence Berkeley Laboratory \\ University of Califomia \\ Berkcley, CA 94720
}

January, 1988

This work was supported by the Assistant Secretary for Conservation and Renewable Energy, Oflice of Building and Community Systems, Building Systems Division and by the Director, Office of Encrgy Rescarch, Office of Health and Environmental Research, Human Health and Assessments Division and Pollutant Characterization and Safety Research Division of the U.S. Deparment of Energy (DOE) under Contract No. DE-AC03-76SF00098. It was also supported by the Office of Environmental Engineering Technology Demonstration, Office of Research and Development of the U.S. Environmental Protection Administration (EPA) through interagency agreement .DW89931876-01-0 with DOE. 


\begin{abstract}
The ${ }^{222} \mathrm{Rn}$ (radon) concentrations in the living area, the basement, and the underlying soil of a New Jersey home have been measured at half-hour intervals over the course of a year, as have indoor and outdoor temperatures, wind speed and direction, and indoor-outdoor and basementsubslab pressures; in addition, periods of fumace operation have been logged. We generalize and extend an existing radon entry model in order to demonstrate the dependence of the radon concentrations on the environmental variables and the extent of fumace use. The model contains parameters which are dependent on geological and structural factors which have not been measured or otherwise determined: statistical methods are used to find the best values of the parameters. The non-linear regression of the model predictions (over time) on the measured living area radon concentrations yields an $\mathrm{R}^{2}$ of 0.88 .
\end{abstract}

\title{
DISCLAIMER
}

\footnotetext{
This report was prepared as an account of work sponsored by an agency of the United States Government. Neither the United States Government nor any agency thereof, not any of their employees, makes any warranty, express or implied, or assumes any legal liability or responsjbility for the accuracy, completeness, or usefulness of any information, apparatus, produst, of process disclosed, or represents that its use would not infringe privately owned rights. Reference herein to any specific commercial product, process, or service by trade name, trademark, manufacturer, or otherwise does not necessarily constitute or imply its endorsement, recommendation, or favoring by the United States Government or any agency thereof. The views and opinions of authors expressed herein do not necessarily state or reflect those of the United States Government or any agency thereof.
} 


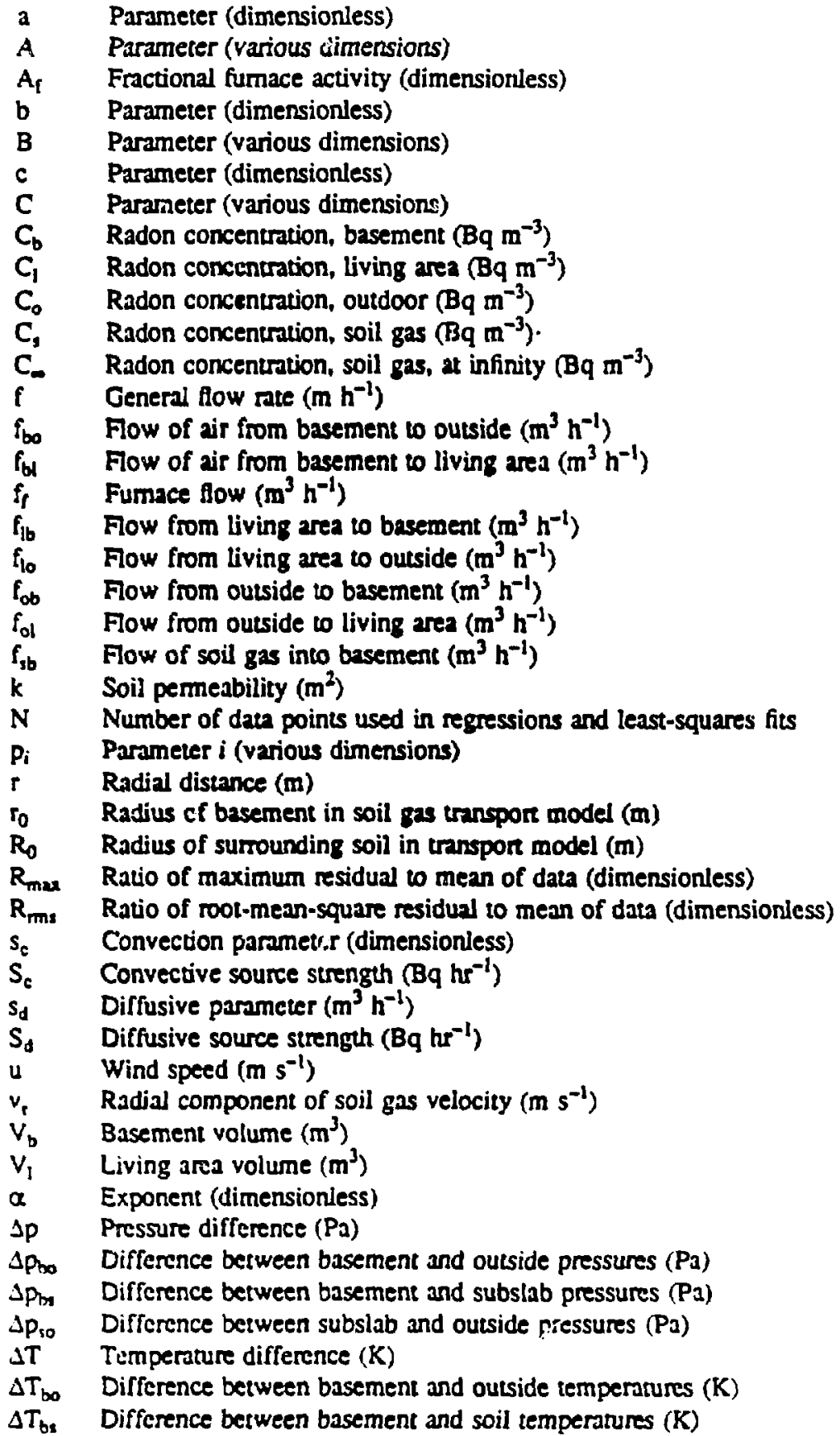


$\lambda_{\mathrm{R}} \quad$ Radon decay constant $\left(\mathrm{h}^{-1}\right)$

$\mu \quad$ Viscosity of air $\left(\mathrm{kg} \mathrm{m}^{-1} \mathrm{~s}^{-1}\right)$

Introduction

Considerations of public health require that residences with elevated ${ }^{222} \mathrm{R} \pi$ (radon) concentrations be identified and that action to reduce the levels be taken. Since exposure is cumulative and since the radon concentration in a house generally varies over time. the only valid measurement technique is a year-long integration - normally, but not necessarily, using etched track detectors. It is, unfortunately, impractical to carry out such measurements for the entire housing stock of the country, so that some means will have to be found of identifying those houses whose concentrations are in excess of some, as yet undecided, action level. A useful part in the development of such a means may be played by a mathematical model of the process of radon entry, distribution, and removal.

A model should, by increasing our understanding of this process, enable us to use our knowledge of geological, environmental, and structural conditions to predict the likely location of houses with elevaled concentrations; it should, once the parameters applicable to a given house are determined by short-term measurements, allow us to predict the variation in concentration with time: it should, again assuming that the parameters have been determined, assist us in selecting appropriate remedial methods.

The first step in the creation of a model was taken by Nazaroff, et. al. (1), who suggested that the observed variation in radon concentration in one house could be accounted for by the combination of diffusive and (pressure-driven) convective sources, the former producing a concentration varying inversely with the air exchange rate and the latter a constant concentration. D'Outavio and Dietz (2), responding to the Nazaroff paper, developed the model further by introducing explicit expressions for the dependencies of the soil gas concentration and the air exchange rate on the indoor and outdoor temperatures, the wind speed, and the barometric pressure. They then applied their model to the data of (1) with some success.

Arvela and Winqvist (3) climinated the necessity for considering the air exchange rate explicilly by introducing into the radon model the air infiltration model (the LBL model) of Sherman and Grimsrud $(4,5)$. They also identify the driving force of the transpor of soil gas into the structure as the stack effect (which also drives the air exchange), but neglect winddriven transport and both temporal and spatial variations in soil gas concentration. They apply their model to annual and diumal variations in radon in Finnish houses, with some success in predicting the ratios of winter to summer levels.

We will combine and extend the approaches of (2) and (3) in order to create a model suitable for a two-zone (basement and living area) house, in which the source will consist solciy of a convection term (diffusion being neglected), which is dependent on the soil gas concentration". The source strength, the soil gas concentration, and the air exchange rate will depend on the indoor-outdoor or indoor-soil temperature difference, the wind speed, and the extent of fumace operation, the fumace having the capabilities of depressurizing the basement and increasing the inter-zone air exchange by mixing; barometric pressure will be neglected. 
We shall compare the predictions of the model with data obtained over the course of a year in a New Jersey house with a below-grade basement, using three-day averages of data taken at half-hour intervals. The model is, however, not limited to houses with basements; with suitable changes, those built over crawl spaces or on slabs can be accommodated.

\section{Theory}

We assume that a house is divided into two zones, namely the basement and the living area, of which only the former has a shell in contact with the soil. If the basement pressure is lower than the outside pressure at the surface of the soil, a pressure field is created in the soil and air flows from outside to basement through the permeable soil, increasing in radon concentration dv :ing the period of transport because of the decay of the radium in the soil granules. The tmanspon lime depends inversely on the velocity of the air (which varies from point to poin:) and directly on the distance travelled; the radon concentration of the air at the point of entry into the basement will have the same general dependence. If the basement has a dirt floor, the radon-bearing air enters directly; otherwise, it passes through cracks or other openings in the walls and floor. In either case, air arrives at the basement by a number of paths and its radon concentration depends in a complex manner on the nature of the velocity field. Even if the physical situation is simplified as much as possible, the equation of mass transport cannot be solved exactly, but we can devise a mathematical model whose solution displays the dependence of concentration on path length and velocity.

If we represent the basement schematically as a depressurized hemisphere of radius $r_{0}$. surrounded by a homogeneous and isotropic hemisphere of soil of radius $R_{0}$, the radial component of the velocity of the soil gas will be found from Darcy's law to be

$$
v_{r}(r)=\frac{R_{0} r k \Delta p_{s 0}}{\mu\left(R_{0}-r_{0}\right) r^{2}}
$$

where $v_{\mathrm{r}}$ is the radial component of the velocity $\left(\mathrm{m} \mathrm{s}^{-1}\right), \mathrm{k}$ is the permeability of the soil $\left(\mathrm{m}^{2}\right)$, $\Delta p_{s o}$ is the difference between the subslab and outside pressures $(\mathrm{Pa}), \mu$ is the viscosity of air $\left(\mathrm{kg} \mathrm{m}^{-1} \mathrm{~s}^{-1}\right)$, and $\mathrm{r}$ is the radial distance from the center of the sphere (m). (If there is no slab, $\Delta p_{s u}$ becomes $\Delta p_{b o}$, the basement-outside pressure difference.) When equation 1 is introduced into the equation of mass transport, with the boundary condition $C_{3}=0$ at $r=R_{0}$, we find that the colicentration at the inner sphere is

$$
C_{s}\left(r_{0}\right)=C_{-}\left\{1-\exp \left[-\frac{\lambda_{R} \mu\left(R_{0}-r_{0}\right)\left(R_{0}^{3}-r_{0}{ }^{3}\right)}{3 R_{0} \sigma_{0}\left|\Delta p_{s o}\right|}\right]\right\} .
$$

where $C_{\text {, }}$ is the soil gas radon concentration $\left(\mathrm{Bq} \mathrm{m}^{-3}\right), \mathrm{C}_{m}$ is the maximum possible soil gas

Lourciro (6), Mowris (7), and Mowris and Fisk (8) have applied numerical lechniques to the problem of soit gas entry into depressurized subsurface besements. We consider their methods too elabonte to be included in the present model, but the highly schematic approach to soil gas entry used here thould ultimately be examined in the light of their work. 
concentration (the concentration infinitely far from the basement and surface), and $\lambda_{R}$ is the radon decay constant $\left(\mathrm{h}^{-1}\right)$. This equation applies only to the case of a depressurized basement. We see that $C_{3}$ increases with increasing path length and decreases with increasing velocity and hence with increasing permeability and pressure difference. The expression of equation 2 will take on a similar, but not identical, form to that of D'Ottavio (2) when the argument of the exponential is small, which will occur when either $\mathrm{k}$ or $\Delta \mathrm{p}_{\mathrm{so}}$ is large.

For an actual depressurized basement, the pressure field in ine surrounding soil depends on the sizes, shapes, and positions of the cracks or other openings. The velocity field depends on the pressure field and on the soil permeability, which may not be uniform: there are likely to be inhomogeneities and preferred flow paths; gravel having a permeability quite different from the surrounding soil may underlie the slab. The radon concentration field depends on the velocity field and on the distribution of radon sources, which is generally assumed to be uniform. The soil gas radon concentration at some point of measurement may be represented by something like equation 2, but we should not expect that equation to provide more than an indication of the dependence of radon flux on the depressurization of the basement and the average permeability of the underlying and surrounding soil.

From the mass-balance, the steady-state radon concentration in the basement is

$$
C_{b}=\frac{f_{o b} C_{a}+s_{d}+s_{c}+f_{l b} C_{l}}{\lambda_{R} V_{b}+f_{b o}+f_{b l}} .
$$

where $C_{b}, C_{0}$, and $C_{1}$ are the basement, outdoor, and living area radon concentrations, respectivcly $\left(\mathrm{Bq} \mathrm{m} \mathrm{m}^{-3}\right), \mathrm{S}_{\mathrm{d}}$ and $\mathrm{S}_{\mathrm{c}}$ are the diffusive and convective sources, respectively $\left(\mathrm{Bq} \mathrm{hr} \mathrm{h}^{-1}\right.$, both of which are assumed to vanish when the basement is pressurized with respect to the underlying and surrounding soil, $f_{o b}, f_{b b}, f_{b l}$, and $f_{b o}$ are the volumetric flow rates from outside to basement, from living area to basement, from basement to living area, and from basement to outside, respectively $\left(\mathrm{m}^{3} \mathrm{hr}^{-1}\right)$, and $\mathrm{V}_{b}$ is the basement volume $\left(\mathrm{m}^{3}\right)$. Similarly, the steadystate living area concentration is

$$
c_{l}=\frac{f_{b l} C_{b}}{\lambda_{R} V_{l}+f_{l o}+f_{l b}},
$$

where $f_{l o}$ and $f_{\mathrm{lb}}$ are the living area to outside and living area to basement lows, respectively, and $V_{1}$ is the living area volume.

We shall make the following assumptions: 1) the product of the radon decay constant and the basement volume is negligible with respect to the flow rates in the denominator, 2) the outside radon concentration is negligible; 3 ) the radun concentration in the soil gas is much greater than that in the basement, so that the diffusion term may be represented as a constant multiple of the soil gas concentration; 4) the flow of soil gas is negligible comparcd with the llow of air entering the basement from the outside. Assumption 1 is generally applicable; the remaining assumptions are applicable to the house under consideration herc, but may not be appropriate to all situations. With these assumptions, the introduction of equation 4 into equation 3 yiclds 


$$
C_{b}=\frac{\left(s_{d}+s_{c} f_{s b}\right) C_{s}\left(1+f_{b b} / f_{l o}\right)}{f_{b o}+f_{b l}+f_{b o} f_{l b} / f_{l o}}
$$

where $s_{d}$ is the diffusion parameter $\left(\mathrm{m}^{3} \mathrm{~h}^{-1}\right), s_{c}$ is the convective parameter (dimensionless), and $f_{s t}$ is the flow across the slab $\left(\mathrm{m}^{3} \mathrm{~h}^{-1}\right)$.

We now assume that the flow from living area to basement is entirely due to furnace opcration, that the fow from basement to living area is the sum of the fumace flow and a term directly proportional to the living area to outside flow, and that the basement to outside flow is a constant multiple of the living area to outside flow, i.e., that

$$
\begin{gathered}
f_{l b}=a A_{f} f_{l o}, \\
f_{b l}=\left(a A_{f}+b\right) f_{l o} .
\end{gathered}
$$

and

$$
f_{b 0}=c f_{10} \text {, }
$$

where $a, b$, and $c$ are dimensionless parameters. Introducing equations 6,7 , and 8 into cquation 5 gives

$$
C_{b}=\frac{\left(s_{d}+s_{c} f_{s b}\right) C_{s}\left(1+a A_{f}\right)}{\left[a+c+b(1+c) A_{f}\right] f_{l o}} .
$$

We see that, when the furnace is not in operation, the basement radon concentration is simply the quotient of a source term and an air exchange rate consisting of two terms whose combination equals the outside to basement flow; when the fumace is in operation, assuming the furnace low to dominate other flows between the two interior zoncs, the air exchange term becomes the sum of the livin: area to outside and basement to oulside flows, which is exactly equal to the total now into the house. With the furnace off, the house can be represented by the two-zone model; with the furnace on, the air of the two zones is mixed and the house is effectively a single zone. The combination of equations 4,6 , and 7 provides an expression for the living area concentration in terms of the basement concentration:

$$
C_{l}=\frac{\left(a A_{f}+b\right) C_{b}}{1+a A_{f}}
$$

The flow across any part of the building shell to or from the outside will depend on the pressure differences produced by the stack effect and the flow of wind over the structure (4); it may also depend on a pressure difference produced by fumace operation. If we represent the average effect of the fumace during a period of time by the fraction of that time during which it is in operation, we may extend the LBL air exchange model by writing

$$
f=\left(A|\Delta T|+B u^{2}+C A_{f}\right)^{\alpha},
$$

where $f$ is the flow rate $\left(\mathrm{m}^{3} \mathrm{~h}^{-1}\right), \Delta \mathrm{T}$ is the temperature difference that drives the flow $(K), u$ 
the wind speed $\left(\mathrm{m} \mathrm{h}^{-1}\right), A_{f}$ is the fractional furnace activity (dimensionless), and $\alpha$ is an exponent whose value lies between 0.5 (turbulent flow) and 1.0 (laminar flow). The dimensions of the parameters A, B, and C depend on the value of $\alpha$. In the LBL model, where $\alpha$ is assumed to be $0.5, A$ is written as $\left(L f_{s}\right)^{2}$ and $B$ as $\left(\mathrm{Lf}_{w}\right)^{2}$, where $L$ is the leakage area of the structure and $\mathrm{f}_{\mathrm{s}}$ and $\mathrm{f}_{\mathrm{w}}$ are, respectively, the stack and wind parameters. It is the ratio of the latter two which will prove to be important here; the ratio of $f_{w}^{2}$ to $f_{3}^{2}$ is generally on the order of $2 \mathrm{~m}^{-2} \mathrm{~h}^{2} \mathrm{~K}$ for a house, but may be considerably smaller when the basement is considered as a separate zone because of the reduced influence of the wind.

The flow across the slab is given by an equation identical to equation 11 , but when the flow is used as par of a source term rather than as an air exchange term we are intcrested only in flow into the basement, so that conditions of zero furnace activity, zero wind speed, and negative $\Delta T$ are to be presumed to produce no flow of soil gas. It is not immediately clear whether the pressure at the basement floor is controlled by the temperature difference between the interior and the soil at slab level or by that between inside and outside. We shall discuss this question furcher below. The appropriate value of $\alpha$ in equation 10 depends on the nature of the openings in the slab (7); we shall assume the value to be 1.0, but with the caveat that the subject requires additional study.

We shall assume that the flow across the soil is driven by the same pressures that drive the llow across the slab. Combining equations 2 and 11, noting that, from equation 1, the exponent $\alpha$ is 1.0 , absorbing certain factors into parameters, and renumbering the parameters, we lind

$$
C_{s}=p_{1}\left\{1-\exp \left(-\frac{1}{p_{2}|\Delta T|+p_{3} u^{2}+p_{4} A_{f}}\right)\right\}
$$

where we have once again left the question of the appropriate $\Delta T$ open. Similarly, combining equations 9 and 11 yields, with some rewriting,

$$
C_{b}=\frac{\left(p_{s}+p_{6}|\Delta T|+p_{j} u^{2}+p_{g} A_{f}\right) C_{s}\left(1+p_{g} A_{f}\right)}{\left(\left|\Delta T_{b o}\right|+p_{10} u^{2}+p_{11} A_{f}\right)^{0.5}\left(1+p_{12} A_{f}\right)},
$$

where $\mathrm{C}_{3}$ may be taken as indicating either the measured value (i.s we are simply testing equation 13) or the value found from equation 12 (if we are testing a complete model). For compleleness, we rewrite equation 10 as

$$
C_{l}=\frac{\left(p_{13}+p_{14} A_{f}\right) C_{b}}{1+p_{14} A_{f}},
$$

where $C_{b}$ indicates either the measured value or the result of equation 13. The number of parameters, 14, is clearly too large for the model to be useful, so that considerable simplification of the equations is necessary; we shall discuss these simplifications below, after we have underaken an initial examination of the data.

The parameters of the model will be deterimined by least-squares fitting, i.c., we minimize the sum of the unweighted squares of the differences between predicted and meastured values; the method used is a finite-difference Levenberg-Marrigardt algorithm (routine ZXSSQ 
of double precision IMSL). The data used will be three-day averages of data taken at halfhour intervals; this choice permits clarity of graphicai presentation and eliminates a considerable amount of noise, while preserving the major fluctuations of the data. We expect the predictions of the model to depart from the data to some extent due to our neglect of the time constants involved in the full equations. The quality of the fit to the data will be indicated by $\mathrm{R}^{2}$, defined as the explained sum of squares divided by the sum of the explained and unexplained sums of squares, i.e..

$$
R^{2}=\frac{\sum_{1}^{N}\left(\hat{C}_{i}-\bar{C}\right)^{2}}{\sum_{i}^{N}\left(C_{i}-\bar{C}\right)^{2}+\sum_{1}^{N}\left(\hat{C}_{i}-C_{i}\right)^{2}}
$$

where $\hat{C}_{i}$ represents any calculated concentration, $C_{i}$ the measured three-day average concentration, and $\bar{C}$ the mean of that concentration. $R^{2}$, as defined by equation 15 , should be used with some caution; it is not directly compamble to the $\mathrm{R}^{2}$ used in linear regression. The significance of the results will be indicated by the $F$ - and t-tests. All values of $F$ used in the text are significant at greater than 0.9999. We shall use the ratio of the RMS resiciual and the mean. which we shall call $R_{\text {ma, }}$ and the ratio of the maximum residual and the mean, $R_{\text {max }}$ as additional indicators of quality where the values of $\mathbf{R}^{2}$ for competing models are similar.

\section{Results}

\section{Qualitative Description}

The house under consideration here is a two-story single-family dwelling with a basement, located in north central New Jersey. It was selected as the control for a year-long study of the effectiveness of remedial action in six other houses in the same general area (9). As a parn of the arrangement with the owner, it was agreed that remedial action would be taken near the end of the study, so that data for the house in its original configuration covers less than a full year. The basement is almost entirely below grade: it contains a forced-air furnace whose ductwork has been observed to be leaky. The basement has a volume of $220 \mathrm{~m}^{3}$; the volume of the entire house is $580 \mathrm{~m}^{3}$.

Radon concentrations were measured in the soil below the basement slab, in the basement itsclf, and on the first ncor using continuous raden monitors (CRMs), whose operation involves the pumping of air through scintillation (Lucas) cells and detection of the scintillations by a photomultiplier. Environnental measurements included temperatures at several indoor locations. outdoors, and at five depths in the soil (the greatest being $100 \mathrm{~cm}$ ), wind speed and direction, barometric pressure, and precipitation. Differential pressures were measured between the top and bottom of the basement slab, between the first floor and the basement, and across the four walls scparating the bascment from the outside air. Fumace operation was measured on a binary (on/off) basis. All data was logged automatically at half-hour intervals and retrieved biweckly. 
Figures 1 and 2 display the variations between 18 September 1986 and 9 July 1987 of the absolute value of the basement-subslab pressure difference $\left(\Delta \mathrm{p}_{\mathrm{bs}}\right)$, the fraction of the period during which the furnace was operating $\left(A_{f}\right)$, the basement-outdoor temperature difference $\left(\Delta \mathrm{T}_{\mathrm{bo}}\right)$, the difference between the basement temperature and the temperature of the soil at a depth of $100 \mathrm{~cm}\left(\Delta T_{b s}\right)$, and the three radon concentrations $\left(C_{l}, C_{b}\right.$, and $\left.C_{s}\right)$. All are depicted by solid lines, except $\Delta T_{b s}$, which is depicted by a dashed line; the use of lines rather than discrete points is necessary for clarity. Soil gas radon data was not collected during much of the first two months of the study; other gaps in the data indicate periods of instrument failure. Variations in the pressure difference between the first floor and the basement could not be shown to be related to the changes in the radon concentrations and will not be discussed further. Periodic failures of the pressure sensors due to moisture precluded the use of the basement-outdoor pressure difference data for the full collection period, although the data are useful for the investigation of shorter periods; in general, the variations are similar to those of the bascment-subslab pressure. Precipitation and barometric pressure will not be discussed in this paper, their effects on soil transport being poorly understood. The wind speed data are used, but have not been depicted. The wind direction data are not used in this paper, changes in wind direction may affect air exchange and soil gas transport, but the nature of the change is not casy to characterize.

Examination of figure 1 shows that $\Delta \mathrm{p}_{\mathrm{b}}$ is qualitatively related to $\Delta \mathrm{T}_{\text {bo }}$ and that it appears to be related to the fumace activity, particularly during January and February, i.c., the fumace does seem to depressurize the basement. Since furmace activity is correlated with $\Delta T_{\text {bo }}$ and wind speed, the exact nature of the effect of each on the pressure may be difficult to determine.

The soil gas concentration shows an inverse relationship with $\Delta T_{b o}$ and the possibility of a similar relatiouship with $A_{f}$. This is consistent with eq!!ation 2, with the llow, and hence $\Delta \mathrm{p}_{\mathrm{so}}$ given by equation 11 . The basement radon concentration falls into four distinct periods: a period of sharp fluctuations from Scptember to early November, a pericd of mild fluctuations with a generally rising tendency from Novernber through February, a return to sharp fluctua tions at a diminished average level irom February through June, and a two-weck period oi clevated levels in Junc, which reflects the closure of the house during the vacation of the occupants. The basement concentration does not appear to be well correlated with the soil gas radon; in particular, there is no indication that the sharp drop in $C_{1}$ during January has any efrect at all on $\mathrm{C}_{\mathrm{b}}$.

The living area modon concentration falls into the same four periods as $C_{b}$, but the ratio of $\mathrm{C}_{l}$ to $\mathrm{C}_{\mathrm{b}}$ is much greater in the winter than in the other seasons. The rise in the concentration during the vacation period is much more dramatic than that in $C_{b}$; the fluctuations in $C_{l}$ are generally wider than those in $C_{b}$.

\section{Basement-Subslab Pressure}

Although equation 11, which combines stack-, wind-, and fumace-driven flows in quadrature, cannot necessarily be used to represent the pressure driving the flows (4), we will use an cquation of similar form for purposes of examining the correlation between the measured 
basement-subslab pressure difference and the variables on the r.h.s. of the equation. We assume, then

$$
\Delta p_{b s}=p_{1}\left|\Delta T_{b o}\right|+p_{2}\left|\Delta T_{b s}\right|+p_{3} u^{2}+p_{4} A_{f} .
$$

Performing the regression $(\mathrm{N}=82)$ and using the t-test to determine the most significant variables, we find

$$
\Delta p_{b s}=0.09\left|\Delta T_{b s}\right|+4.0 A_{f},
$$

with an $R^{2}$ of 0.82 , an $F$ of 183 , and $t$ values for the two parameters which are also significant at $>.9999$, i.e., at least for the house being considered l:ue, the basement-soil temperature difference and the fumace activity arpear to be the most important determinants of the basement-subslab pressure difference and, therefore, of the flow of soil gas. On figure 1, equation 17 is plotted against the measured pressure difference as a dashed line.

It is necessary to state, however. that the results are not conclusive. In the following table, we provide the values of $R^{2}$ and $F$ for the regression of several combinations of variables

\begin{tabular}{|c|c|c|c|}
\hline Case & Variables & $\mathrm{R}^{2}$ & $\mathbf{F}$ \\
\hline 1 & $\Delta T_{b y}, A_{f}$ & 0.82 & 1 \\
\hline 2 & $\Delta T_{b,}, A_{f}, u^{2}$ & 0.82 & ( \\
\hline 3 & $\Delta \mathrm{T}_{\text {bo }}, \mathrm{A}_{\mathrm{f}}$ & 0.75 & ( \\
\hline 4 & $\Delta \mathrm{T}_{\mathrm{bo}}, \mathrm{u}^{2}$ & 0.69 & \\
\hline 5 & $\Delta T_{\text {bo, }} A_{f}, u^{2}$ & 0.77 & \\
\hline 6 & $\Delta T_{b y} u^{2}$ & 0.50 & \\
\hline
\end{tabular}
on the measured $\Delta \mathrm{p}_{b s}$.

Since case 2 is inferior to case 1 and case 4 inferior to cas, 3, and since case 5 has an $R^{2}$ oniy marginally superior to that of case 3, we may say that the inclusion of the wind speed in eguation 16 adds nothing to the statistical significance (the combination of the wind speed and $\Delta T_{b s}$, which is not physically reasonable, produces very poor results). The use of $\Delta T_{b s}$ produces slightly superior results to the use of $\Delta T_{b o}$, when each is combined with $A_{f}$.

The relationship between pressure, as represented by the basement-subslab difierence, and temperature, represented by the basement-outdoor or basement-soil differences, wind speed, and fumace activity is considered sufficiently well established to allow the explicit use of the pressure to be dropped in the remainder of the work. This is necessary because of the absence, for many periods, of measurements of the basement-outdoor pressure differences which would be required to determine the air exchange rates; these differences generally parallel the basement-subslab difference, but the similarity is not great enough to allow the use of the iatter as a surrogate. In other words, the combination of temperature, wind speed (which will not be considered insignificant as a factor in determining indoor-outdoor flows), and furnace activity will represent the basement-outdoor pressure difference better than will the measured basement-subslab pressure difference. 


\section{Soil Gas Concentration}

Following the same procedure used with the basement-subslab pressure, we shall include both of the relevant temperature differences in equation 12, so that the predicted soil gas becomes

$$
C_{s}=p_{1}\left\{1-\exp \left[-\frac{1}{p_{2}\left|\Delta T_{b 0}\right|+p_{3}\left|\Delta T_{b b}\right|+p_{4} u^{2}+p_{5} A_{f}}\right]\right\} .
$$

We shall then attempt to select the most significant variables, noting that the procedure is no longer a regression but rather a least-squares fit to the data. We shall examine, in addition to $R^{2}$ and $F, R_{m a}$ and $R_{\max }$. The number of data is 78 . The results are given in the following tablc.

\begin{tabular}{|c|c|c|c|c|c|}
\hline Case & Variabics & $\mathbf{R}^{2}$ & $\mathbf{F}$ & $\mathrm{R}_{\mathrm{ma}}$ & $R_{m}$ \\
\hline I & $\Delta T_{b y}, \Delta T_{b o}, A_{f}, u^{2}$ & 0.66 & 28 & 0.17 & \\
\hline 2 & $\Delta T_{b u=} A_{0} u^{2}$ & 0.66 & 36 & 0.17 & \\
\hline 3 & $\Delta T_{b y} A_{f}$ & 0.62 & 41 & 0.18 & \\
\hline 4 & $\Delta T_{b,}, u^{2}$ & 0.46 & 22 & 0.21 & \\
\hline 5 & $\Delta T_{b}$ & 0.38 & 23 & 0.22 & \\
\hline 6 & $\Delta T_{b o}, A_{f}, u^{2}$ & 0.63 & 32 & 0.17 & \\
\hline 7 & $\Delta T_{b 00}, A_{f}$ & 0.56 & 32 & 0.19 & \\
\hline 8 & $\Delta T_{b o} u^{2}$ & 0.57 & 33 & 0.18 & 3. \\
\hline 9 & $\Delta \mathrm{T}_{\text {bo }}$ & 0.47 & 34 & 0.20 & 3. \\
\hline 10 & & 0.56 & 48 & 0.19 & 2.9 \\
\hline 11 & & 0.25 & 13 & 0.25 & \\
\hline
\end{tabular}

Cases 4, 5, and 9 may be ruled out because of low $R^{2}$. Case 10 must be nuled out on physical grounds, since there is depressurization when the fumace is not operating. Case 1, which included both temperature differences, is not superior to case 2 and has only a slightly larger $\mathrm{R}^{2}$ than case $6 ;$ it, too, may be ruled out. Of the remaining cases, those involving $\Delta T_{b y}$ are statistically more significant that those involving $\Delta T_{b o}$ although the difference is not large. The highest value of $F$ occurs for the combination of $\Delta T_{b e}$ and $A_{f i}$ we suggest, then, that the best representation of the soil gas may be

$$
C_{s}=146000\left\{1-\exp \left[-\frac{1}{0.039\left|\Delta T_{b s}\right|+2.3 A_{f}}\right]\right\} .
$$

We do not expect the parameters of equation 19 to be equal to the equivalent ones of equation 17, but the ratio of the two should be similar. In the present case, the ratio of the cocfficients of $A_{f}$ and $\Delta T_{b z}$ is 59 , while for equation 17 it is 44 ; given the large (and difficult to determine) unccrtainties involved in the calculations, these numbers are in reasonable agrecment. The dashed line for $C_{3}$ in figure 2 shows the predicted values based on this equation (figure 2 includes the vacation period, which was not modelled).

We do not suggest, based on the limited evidence of this section, that the wind speed and the bascment-outdoor temperature difference can be ruled out as factors influencing soil gas 
concentration, even in the present case. While single-point measurements of indoor radon can be taken as representative of a room concentration if one has reason to believe that the air is well mixed, it is by no means established that single-point soil gas measurements represent anything more than concentrations prevailing in the immediate area of the sensor. Both the experimental and theoretical work on the subject of soil gas is in an early stage, but we shall show that a soil gas model may not be required to predict indoor concentrations.

\section{Basement Concentration}

We noted that the basement concentration falls into three distinct periods, apart from the vacation period, which will not be modelled. The two periods during which relatively large nuctuations occur will hereinafter be referted to as "summer"; the remaining period, whicil we will take as running from December 4 through March 12, will be referred to as "winter". There are 77 data points, of which 28 occur in winter.

When we model the basement concentration using equation 13 with $\mathrm{C}_{\mathrm{z}}$ equal to the measured soil gas concentration and with a source term containing only $\Delta T_{\text {bo }}$ and $u$, the best fit to the data produces an $R^{2}$ of 0.65 , an $R_{\text {mas }}$ of 0.18 , and an $R_{\text {max }}$ of 0.75 . Elimination of the wind speed and fumace activity terms actually increases $R^{2}$ to 0.68 , at the price of increasing $R_{m \text { m }}$ to 0.22 and $R_{\text {max }}$ to 0.84 ; in this case, there is just one parameter and the $F$ is 153 . The results indicate the doubtful utility of the wind speed and fumace terms in predicting the basement concertration, at least when the measured soil gas values are used.

We shall examine the full model, in which equation 13 is used with the soil gas values given by equation 12. Equation 13 contains 4 source terms; the results of the section on soil gas suggest that we test the model with a diffusion term and either $\Delta T_{b}$ and $A_{f}$ or $\Delta T_{b o}$ and $u$ as the sources. When this is done, it is apparent that the large fluctuations in the basement radon concentration in summer can be accounted for only if the indoor-outdoor temperature difference is one of the sources. We test the model with and without a diffusion term included, with and without a wind speed term included in the denominator (as part of the air exchange or removal expression), and with and without a wind speed term included in the numerator (as a part of the source tcrm). For the 77 data, we have the following results.

\begin{tabular}{|c|c|c|c|c|c|c|}
\hline Case & Wind speed & Diffusion & $\mathrm{R}^{2}$ & $\mathbf{F}$ & $\mathbf{R}_{\mathrm{rms}}$ & $\mathbf{R}_{\max }$ \\
\hline 1 & Removal, source & Yes & 0.60 & 15 & 0.12 & 0.53 \\
\hline 2 & Removal & Yes & 0.60 & 18 & 0.12 & 0.54 \\
\hline 3 & No & Yes & 0.62 & 23 & 0.12 & 0.53 \\
\hline 4 & Removal, source & No & 0.63 & 20 & 0.12 & 0.47 \\
\hline 5 & Removal & No & 0.67 & 30 & 0.13 & 0.55 \\
\hline 6 & No & No & 0.68 & 39 & 0.15 & 0.75 \\
\hline
\end{tabular}

It is no: easy to select among competing models on the basis of statistical tests. We must, however, reject case 5 , since a negative parameter, which is physically unacceptable, is predicted. The remaining cases result in generally comparable parameters, except that the absence of a diffusion term in case 4 causes the wind speed parameters to increase sharply 
from their values in case 1; we cannot, therefore, distinguish statistically between soil gas entry due to wind-driven depressurization and entry due to diffusion. If we reject case 6 on the basis of its large maximum residual, which is caused by the absence of any source term when $\Delta T_{\text {bo }}$ is small, the best results appear to be those of case 4 , although it is unclear why the addition of a diffusion term (case 1) reduces $\mathrm{R}^{2}$ and increases the size of the maximum residual. The parameters of case 4 are given in the following equation, which is also plotted against the measured value of $C_{b}$ in figure 2 .

$$
C_{b}=\frac{\left(320\left|\Delta T_{b o}\right|+240 u^{2}\right)\left\{1-\exp \left[-\frac{20000}{320\left|\Delta T_{b o}\right|+240 u^{2}}\right]\right\}\left(1+2.2 A_{f}\right)}{\left(\left|\Delta T_{b o}\right|+1.6 u^{2}\right)^{0.5}\left(1+6.1 A_{f}\right)},
$$

The coefficient of $\mathrm{u}^{2}$ in the denominator, $1.6 \mathrm{~K} \mathrm{~m}^{-2} \mathrm{~h}^{2}$, is similar in value to results obtained from the $\mathrm{LBL}$ air exchange model (5), whereas the value obtained in case 1 is much lower.

The values obtained for the diffusion parameter in cases 1-3 are 170, 185, and $141 \mathrm{~Bq}$ $\mathrm{K}^{0.5} \mathrm{~m}^{-3}$, respectively. At a $\Delta \mathrm{T}$ of $10 \mathrm{~K}$ and a wind speed of $1 \mathrm{~m} \mathrm{~h}^{-1}$, these would produce radon concentrations of 50,54 , and $41 \mathrm{~Bq} \mathrm{~m}^{-3}$, respectively; these values are physically reasonable, and are small enough that the neglect of the diffusion term in equation 20 is insignificant.

The results of the test of the model with the soil gas data suggest that we attempt to eliminate the fumace terms from equation 20 . This does not prove successful, resulting in a reduction of $\mathrm{R}^{2}$ to 0.51 ; these terms should be included in the full model. On the other hand, the elimination of the soil gas term from equation 20, i.e., the setting of the argument of the exponential to negative infinity, actually increases the $\mathrm{R}^{2}$ slightly to 0.64 ; the relatively large number of parameters allows the model to compensate for the absence of the soil gas term. Some soil gas term must be included in any physical model, but it may be that an empirical model can be found which will eliminate the need to determine the additional parameter necessitatcd by the inclusion of the soil gas term.

It can be seen from figure 2 that the model does not predict the fluctuations in the winter concentrations very well. This failure is confimed when we divide the data on the basis of furnace activity: the fit of the model to the summer data ( $A_{f}$ Iess than 0.1 ) results in values of $R^{2}$ of the order of 0.7 ; for the winter data ( $A_{f}$ greater than 0.1 ), $R^{2}$ is less than 0.1 . A model in which the source is a combination of $\Delta T_{b o}$ and $u$ during the summer and of $\Delta T_{b s}$ and $A_{f}$ during the winter produces, when fit to the data, an $R^{2}$ of 0.70 , an $F$ of 20 , an $R_{\mathrm{mms}}$ of 0.11 , and an $R_{\max }$ of 0.44 . The best values of the parameters are given by

$$
C_{b}=\frac{\left(300\left|\Delta T_{b o}\right|+44 u^{2}\right)\left\{1-\exp \left[-\frac{24000}{300\left|\Delta T_{b o}\right|+44 u^{2}}\right]\right\}\left(1+0.68 A_{f}\right)}{\left(\left|\Delta T_{b o}\right|+0.033 u^{2}\right)^{0.5}\left(1+3.4 A_{f}\right)} .
$$

for the summer, and 


$$
C_{b}=\frac{\left(160\left|\Delta T_{b s}\right|+11000 A_{f}\right)\left\{1-\exp \left[-\frac{24000}{160\left|\Delta T_{b s}\right|+11000 A_{f}}\right)\right\}\left(1+0.68 A_{f}\right)}{\left(\left|\Delta T_{b o}\right|+0.033 u^{2}\right)^{0.5}\left(1+3.4 A_{f}\right)} .
$$

for the winter. This model is to be regarded as empirical; its physical basis, if any, is unclear. As with equation 20, the soil gas term can be removed from equations 21 and 22 without loss of statistical significance. For purposes of comparison, the results are plotted, together with the data and the results of equation 20, in figure 2.

\section{Living Area Concentration}

To test the validity of the part of the model relating living area and basement concentrations, we use cquation 10 with the measured values of $C_{b}$. The result is

$$
C_{l}=\frac{\left(0.24+5.1 A_{f}\right) C_{b}}{1+5.1 A_{f}}
$$

with $R^{2}=0.93, F=537, R_{m s}=0.12$, and $R_{\max }=1.9$, this occurring when $C_{1}$ is relatively small. The statistical significance of the result indicates the importance of fumace operation in the transport of radon between zones.

From equations 13 and 14 , we see that the fully modelled living area concentration will be given by an expression of the form of equation 20 with different parameters. When we altempt to fit the model to the data, we find that the argument of the exponential governing the soil gas concentration becomes positive, which is physically impossible. It is probable that the result is due to the inadequacy of the model of soil gas transport. When we simplify the model by climinating the soil gas tem, we find

$$
C_{l}=\frac{\left(78\left|\Delta T_{b o}\right|+18 u^{2}\right)\left(1+94 A_{f}\right)}{\left(\left|\Delta T_{b o}\right|+0.41 u^{2}\right)^{0.5}\left(1+59 A_{f}\right)},
$$

with $R^{2}=0.88, F=115, R_{r m s}=\dot{0} .16$, and $R_{\max }=2.2$. The results are excellent, but the wind specd and fumace activity coefficients are quite different from those which were found from the model of basement concentration.

The wind speed can simply be eliminated from the model without loss of statistical signiticance. We have

$$
C_{l}=\frac{81\left|\Delta T_{b o}\right|\left(1+89 A_{f}\right)}{\left|\Delta T_{b o}\right|^{0.5}\left(1+58 A_{f}\right)},
$$

with $R^{2}=0.88, F=200, R_{r m s}=0.16$, and $R_{m u x}=2.3$. The uncertainty in the furmace activity coefficients is, in addition, very large. When we fix the coefficient in the denominator at its value from equation 20 , we find that $R^{2}$ becomes 0.85 , an insignificant loss of quality, that the coefficient of $\Delta T_{b o}$ becomes 100 , and that the coefficient of $A_{f}$ in the numerator becomes 8.2, 
which is similar in magnitude to the coefficients appearing in equation 20.

The predictions of equations 23 and 25 are plotted, together with the data, on figure 2 (recall, once again, that the vacation period has not been modelled). Examination of the figure shows that the predictions on the basis of the measured basement (23) concentration are somewhat better than those of the full model, a result we would expect from a knowledge of the difficulties of the model in predicting the basement concentrations for the winter. Introduction of different source terms for the summer and winter, as in equations 21 and 22, reduces the quality of the fit to $\mathrm{C}_{\mathrm{l}}$. The predictions of the full model for the living area concentration are much better than those for the basement, although the former predictions involve the latter implicitly. The reason is not immediately apparent.

\section{Conclusions}

The prediction of the radon concentration in the living area of a house requires an understanding of the ways in which environmental conditions and house operation produce the flows which cause radon entry, distribution, and removal. If the soil gas concentration at infinity is known, then knowledge of the flow of soil gas allows the prediction of the flux of radon entering the house. (If the outside radon soncentration is not negligible, we must also know the air exchange rate.) If the house has more than one zone. in the sense that there is poor inter-zone mixing of air, then the air exchange rates among the zones and between each zone and the outside must, in principle, be known in order to predict the radon concentration in each zone. In normal situations, a one- or two-zone inodel is adequate.

For a single house, we have shown that the pressure across the basement slab and, hence. the soil gas concentration, is dependent on the indoor-outdoor and indoor-soil temperature differences, the wind speed, and the furnace activity, although the relative importance of each of the independent variables is difficult to determine. The measured soil gas concentration is modelled crudely, with results that are statistically significant, but which may be said to predict only the general trend of the data. In any case, the absence of a good correlation between basement and soil gas concentrations suggests that the soil gas data are determined by local phenomena.

The development of an improved soil gas model requires both additional data and theoretical work. Beginnings have been made on the creation of a numerical model of radon transport into structures; the model should be developed further to take into account different configurations of the subsurface part of the structure and the possibility of inhomogeneities in the makeup of the soil. It should be determined, by field measurements and in controlled experiments, how soil gas concentration varies from point to point in the vicinity of a depressurized structure. Although no radon entry model can be said to be complete without the ability to predict soil gas concentration, if the success of the present model in predicting living area concentrations while neglecting soil gas altogether should be duplicated for other houscs, the question of a soil gas model may become academic.

For the present model, applied to a single house, the predictions of soil gas and basement concentrations have roughly equal statistical significance, with $R^{2}$ on the order of 0.65 . The 
principal problem is the inability of the model to predict either the general trend or the fluctuations of the data obtained during the period of cold weather, although the predicted concentrations are of the correct magnitude. An empirical model for the basement concentration which uses different source terms for summer and winter produces somewhat better results, but its physical basis is obscure. In a two-zone house, the prediction of basement concentrations is merely an intermediate step in the prediction of living area concentrations. It is a step which may be bypassed, but a correct model should have the ability to predict basement concentrations correctly, whether or not they are used; in addition, in a one-zone house, the prediction of the concentration in the area experiencing direct transport of soil gas is essential.

The ability of the model to predict the living area concentration for the New Jersey house is much better than its ability to predict the intermediate (basement and soil gas) concentrations. In fact, the model of equation 25 is simplified to the point that it is uased on just two independent variables: the indoor-outdoor temperature difference and the fumace activity. It is to be expected that the wind speed will be more important in otjer houses than it has proved to be here, but its inclusion, as in equation 24, presents no problems. It is also to be expected that there will be circumstances, such as construction on soil of high permeability, in which a soil gas model will prove essential.

The number of parameters involved in the model, apart from the question of a distinct entry model for cold weather, and assuming the LBL air exchange model to be adequate, is six (sce equation 20). Two of the parameters relate the entry rate of soil gas to the temperature difference and the wind speed. The relationship of these to the structure of the house and the characteristics of the underlying soil is the principal subject for further study. One parameter is simply the ratio of the squares of the wind and stack parameters of the LBL model; it may be determined roughly by an examination of the house and its surroundings. Two parameters are related to furnace operation; it may be possible to reduce these to one, since they appear to be mutually dependent, but more data is necessary before we can be sure of this. In any case, it may be possible to relate them, on an empirical basis, to characteristics of the fumace and its ducting. Finally, one parameter determines the diminution of soil gas concentration due to air transport. It is by no means clear that a knowledge of this parameter will be necessary, but additional measurements and furher development of numerical models should make it possible to detertinc the dependeries of this parameter on soil petmedoiitiy and structural ractors.

\section{Acknowledgements}

We should like to acknowledge the assistance of our colleagues W.J. Fisk, D.T. Grimsrud, and M.H. Sherman in the preparation and review of this paper.

This work was supported by the Assistant Secretary for Conservation and Renewable Energy. Office of Building and Community Systems, Building Systems Division and by the Dircctor, Office of Energy Research, Office of Health and Environmental Research, Human Health and Assessments Division and Pollutant Characterization and Safety Research Division of the U.S. Department of Energy (DOE) under Contract No. DE-AC03-76SF00098. It was also supported by the Office of Environmental Enginecring Technology Demonstration, Office 
of Research and Development of the U.S. Environmental Protection Administration (EPA) through interagency agreement DW89931876-01-0 with DOE. This report has not been subjected to EPA. review. Its contents do not necessarily reflect the views of EPA, nor does mention of firms, trade names, or commercial products constitute endorsement or recommendation for use.

\section{References}

[1] W.W. Nazaroff, H. Feustel, A.V. Nero, K.L. Revzan, and D.T. Grimsrud, "Radon transport into a detached one-story house with a basement". Atmospheric Envirorment, vol. 19. no. 1, pp. 31-46, 1985.

[2] T.W. D'Ottavio and R.N. Dietz, Amospheric Environment, vol. 20, no. 5, pp. 1065 1069. 1986.

[3] H. Arvela and K. Winqvist, "Influence of source type and air exchange on variations of indoor radon concentrations", Finnish Centre for Radiation and Nuclear Safety, Helsinki, Finland, STUK-S51, 1986.

[4] M.H. Sherman and D.T. Grimsrud, "Measurement of infiltration using fan pressurization and weather data' ", Lawre. ıce Berkeley Laboratory, University of Califomia, LBL-10852, 1980.

[5] M.H. Sherman and M.P. Modera, "Comparison of measured and predicted infiltration using the LBL infiltration model", Measured Air Leakage of Buildings, ASTM STP 904, H.R. Trechsel and P. Lagus, Eds., American Society of Testing and Materials, Philadelphia, 1986, pp. 325-347.

16] C. deO. Loureiro, "Simulation of the steady-state transport of radon from soil" into houses with basements under constant negative pressure" , Lawrence Berkeley Laboratory. University of Califomia, LBL-24378, 1987.

[7] R.J. Mowris, "Analytical and numerical models for estimating the effect of exhaust" ventilation on radon entry in houses with basements or crawl spaces" , Lawrence Berkeley Laboratory, University of Califomia, LBL-22067, 1987.

[8] R.J. Mowris and W.J. Fisk, "Modeling the effects of exhaust ventilation on radon entry rates" and indoor radon concentrations" , Lawrence Berkeley Laboratory, University of California, LBL-22939, 1987.

(9] R.G. Sextro, J. Harrison, B.A. Moed, K.L. Revzan, B.H. Turk, D.T. Grimsrud, A.V. Nero, D.C. Sanchez, and K.Y. Teichman, "An intensive study of radon and remedial measures in New Jersey homes: preliminary results", Lawrence Berkelcy Laboratory, University of Califomia, LBL-23128, 1987. 


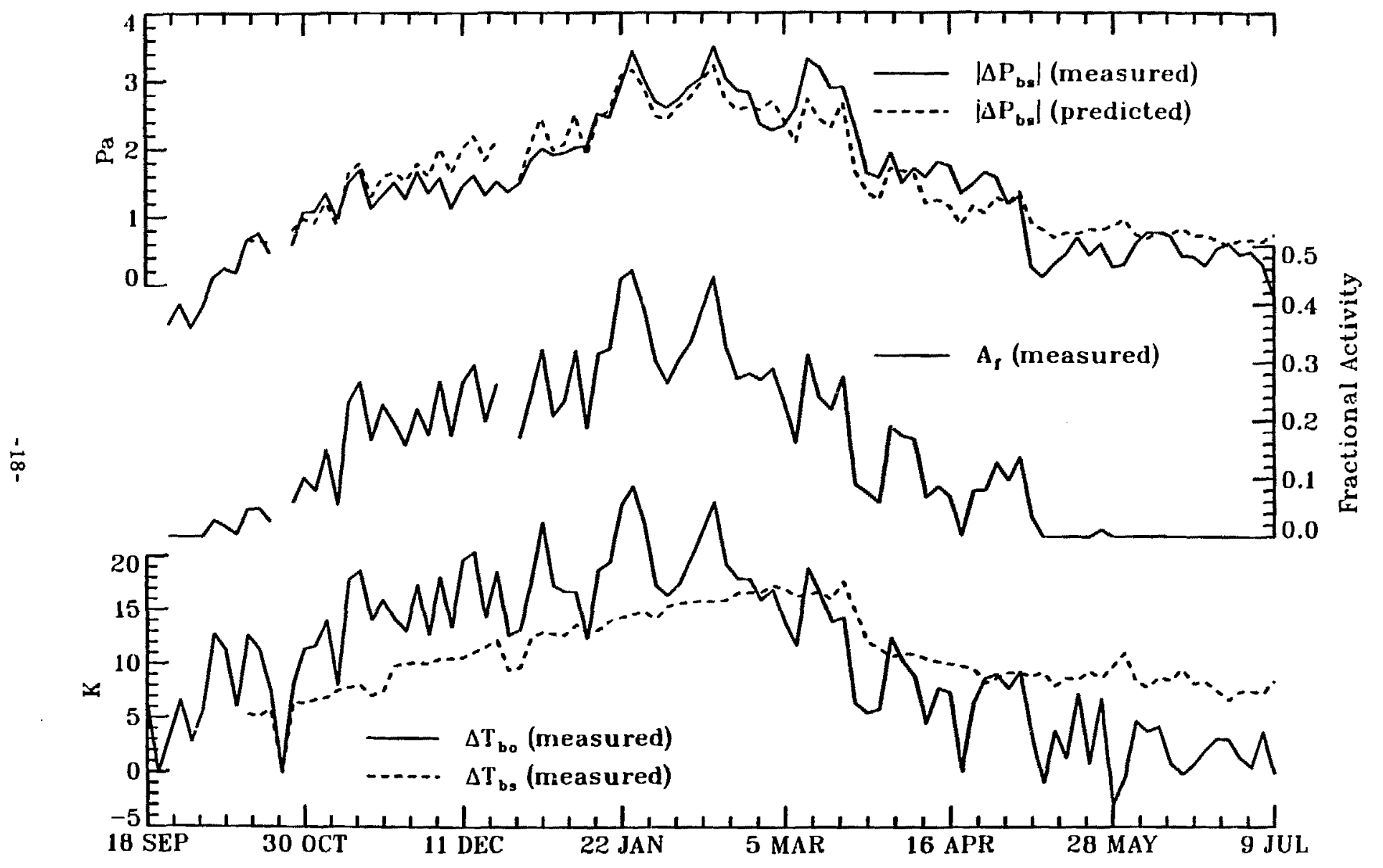

Figure 1. Measured values of subslab-basement pressure, furnace activity, and bascment-outside and bäsement-soil temperatures.

Predicted pressures are taken from equation 17. 


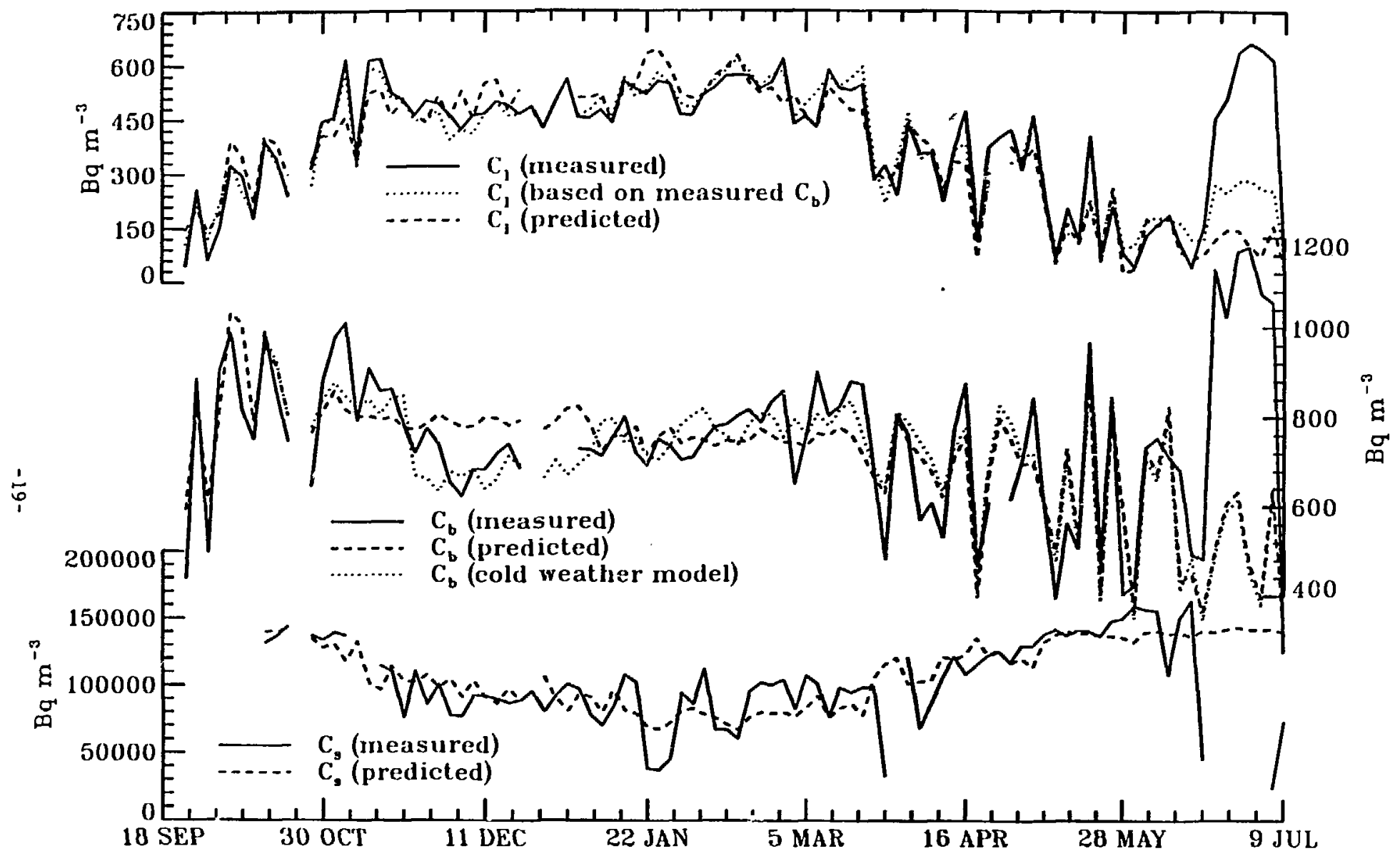

Figure 2. Measured and predicted values of living area, basement, and soil gas radon concentrations. Predicted values are based on equations 23 and $24\left(C_{1}\right), 20,21$, and $22\left(C_{b}\right)$, and $19\left(C_{s}\right)$. 